\title{
MENGGAGAS SOLUSI PEMBELAJARAN BAHASA DI TENGAH PROBLEMA BANGSA (Pembelajaran Bahasa Portugis di Timor Leste)
}

\author{
Agostinho dos Santos Gonçalves \\ Jurusan Bahasa Portugis, Fakultas Ilmu Pendidikan, Institute Superior Cristal \\ Suco Marcarenhas, Rua Estrada de Balide Vera Cruz, Municipio Dili, Timor Leste \\ E-mail: santosagostinho@yahoo.com
}

\begin{abstract}
ABSTRAK
Masyarakat Timor Leste sampai saat ini masih mengeluhkan keberadaan bahasa Portugis sebagai bahasa Nasional. Keluhan tersebut terjadi di kalangan masyarakat umum ataupun di kalangan pendidikan. Rendahnya penggunaan bahasa Portugis di kalangan masyarakat menyebabkan pembelajaran bahasa Portugis memerlukan pemikiran yang serius. Pembelajaran bahasa Portugis belum dilaksanakan sesuai dengan harapan. Guru-guru bahasa Portugis menjalankan tugas mengajarnya tidak didasarkan pada kewenangan dan kompetensi akademik yang dipersyaratkan. Kurikulum pembelajaran belum sepenuhnya mengikuti kurikulum bahasa Portugis yang diadopsi dan diadaptasi dari Portugal. Berdasarkan kondisi tersebut, perlu ditemukan solusi yang mampu memberikan kebermanfaatan hasil belajar kepada para siswa
\end{abstract}

Kata Kunci: solusi, pembelajaran bahasa, bahasa Portugis

\section{INITIATING THE SOLUTIONS OF THE LANGUAGE LEARNING AMONG THE NATION'S PROBLEMS (Portuguese Language Learning in Timor Leste)}

\begin{abstract}
The people of Timor Leste is still complaining about the presence of the Portuguese language as a national language. The complaints are commonly exist among the citizen in the Timor Leste people and in also among the educators in the schools. The Portuguese language is still rarely spoken as national language in the community which led to the Portuguese language becomes serious thought. Portuguese language has not been performed as it expected. Portuguese language teachers are not based on authority and academic competence that required as a language teacher. The curriculum is not fully implementing the Portuguese curriculum which it was adopted and adapted from Portugal. Under these conditions, it is necessary to find a solution that enable the students to gain the satisfaction outcomes of the learning.
\end{abstract}

Keywords: Solutions, language learning, Portuguese

\section{PENDAHULUAN}

Timor Leste sejak kemerdekaan tahun 2002,berdasarkan konstitusi Timor Leste, memiliki 2 bahasa resmi, yaitu bahasa Tetun dan bahasa Portugis. Selain itu, dalam Constitution of the Democratic Republic of East Timor pada Part 1, section 13 tentang Official Languages and National Languages (1) ayat (1) menyebutkan bahwa Tetum and Portuguese shall be the official languages in the Democratic Republic of East Timor, dan (2) ayat (2) menyebutkan bahwa Tetum and the other 
national languages shall be valued and developed by the State. Berdasarkan pernyataan dalam konstitusi tersebut, dapat dijelaskan bahwa bahasa Tetum dan bahasa Portugis merupakan bahasa resmi di Republik Demokrasi Timor Leste (RDTL). Kedua bahasa tersebut dibina dan dikembangkan oleh Negara.

Selain kedua bahasa nasional yang dikembangkan, di Timor Leste juga terdapat bahasa Inggris, bahasa Indonesia, dan sejumlah bahasa daerah yang digunakan di daerah Bekais, Bunak, Dawan, Fataluku, Galoli, Habun, Idalaka, Kawaimina, Kemak, Lovaia, Makalero, Makasai, Mambai, Tokodede, dan Wetarese. Dalam konstitusi, disebutkan bahwa bahasa Inggris dan bahasa Indonesia dijadikan bahasa kerja. Dalam praktik keseharian, masyarakat banyak menggunakan bahasa Tetum Portugis sebagai bahasa pergaulan. Sementara itu, bahasa Indonesia banyak dipakai untuk menulis tugas-tugas pembelajaran, misalnya, mahasiswa di tingkat Perguruan Tinggi.Banyak mahasiswa dan dosen lebih memilih menggunakan bahasa Indonesia sebagai bahasa pengantar dan menulis karangan ilmiah.

Sebelum menjadi Negara merdeka yang berdaulat, Timor Leste merupakan bagian dari Negara Indonesia, yakni provinsi yang ke-27 dengan nama Timor Timur. Di bawah pemerintahan Orde Baru, bahasa Portugis tidak boleh digunakan sebagai bahasa pengantar atautpun sebagai bahasa pergaulan di Timor Timur. Namun, saat ini bahasa Portugis di Timor Leste diajarkan dan dipromosikan secara luas dengan bantuan dari Brasil dan Portugal. Namun, kenyataannya masih banyak kendala dalam perkembangan bahasa Portugis tersebut karena masih terdapat keengganan dari beberapa kalangan generasi muda berpendidikan di Timor Leste.

Masalah pembinaan bahasa di Timor Leste dapat dicermati dari kenyataan yang terjadi dalam pemakaian bahasa, Menurut Laporan Pembangunan PBB 2006, diinformasikan bahwa kurang dari 5\% dari penduduk Timor Leste yang berbicara bahasa Portugis secara fasih. Validitas laporan ini dipertanyakan oleh para anggota Institut Linguistik Nasional Timor yang mempertahankan pendapat bahwa bahasa Portugis diucapkan oleh 25\% dari penduduk Timor. Seiring dengan bahasa lokal lainnya, bahasa Tetum merupakan bahasa yang paling umum digunakan untuk berkomunikasi, sementara itu bahasa Indonesia masih banyak digunakan di media dan perguruan tinggi.

Bertolak dari uraian di atas, dapat dikemukakan bahwa keberadaan bahasa Portugis dalam dunia pendidikan di Timor Leste masih menghadapi banyak masalah. Hal ini disebabkan oleh kekurangsiapan tenaga pendidik dalam penguasaan bahasa Portugis dan belum memadainya sarana pembelajaran yang mampu mendukung kelancaran belajar bahasa Portugis. Sementara ini, guru-guru pengajar bahasa Portugis sebagian besar adalah bukan lulusan program pendidikan bahasa Portugis. Demikian juga, sarana pendukung pembelajaran belum mencukupi untuk mempercepat penguasaan bahasa Portugis.

Uraian di atas menunjukkan bahwa kualitas pembelajaran bahasa Portugis masih belum memadai. Kualitas pendidikan dapat diketahui dari dua hal, yaitu kualitas proses dan produk (Sudjana, 2000:35). Suatu proses pendidikan dikatakan berkualitas apabila proses belajar mengajar (PBM) dapat berlangsung secara efektif dan peserta didik mengalami proses pembelajaran yang bermakna. 
Produk pendidikan disebut berkualitas produk apabila peserta didik menunjukkan tingkat penguasaan yang tinggi terhadap tugas-tugas belajar sesuai dengan sasaran dan tujuan pendidikan.

Bahasa Portugis merupakan bahasa nasional bagi bangsa Timor Leste. Sebagai bahasa nasional, bahasa Portugis diupayakan berperan sebagai wahana komunikasi antar suku bangsa yang mendiami wilayah Timor Leste. Selain itu, bahasa Portugis juga berfungsi sebagai bahasa pengantar dalam komunikasi formal. Karena itu, saat ini bahasa Portugis diupayakan menjadi bahasa pengantar di dunia pendidikan dan menjadi salah satu pelajaran wajib yang harus dipelajari oleh para siswa.

Sebagai bahasa nasional, bahasa Portugis perlu dimasyarakatkan bagi seluruh bangsa di Timor Leste. Salah satu upaya pemasayarakatan bahasa Portugis yang paling efektif adalah melalui proses pembelajaran di sekolah. Agar pemasyarakatan bahasa Portugis melalui pembelajaran tersebut dapat berhasil secara optimal, guru perlu mengembangkan praktik pembelajaran yang lebih inovatif sehingga dapat meningkatkan motivasi belajar siswa dan gaya belajar siswa yang mendukung tercapainya hasil belajar yang maksimal.

Bahasa Portugis akan dapat dikuasai oleh siswa dengan mudah dan lancar jika pembelajaran bahasa Portugis didasarkan pada hasil analisis kebutuhan siswa. Kebutuhan tersebut di antaranya adalah kebutuhan berkomunikasi dalam praktik pembelajaran di kelas atau pun kebutuhan komunikasi di luar kelas. Terkait dengan pernyataan tersebut, dalam praktik pembelajaran, guru perlu mengembangkan bahan ajar bahasa Portugis yang didasarkan pada kebutuhan komunikasi siswa. Dengan demikian, bahasa yang dipelajarinya dapat dipraktikkan langsung dalam komunikasi sehari-hari baik di sekolah maupun di luar sekolah.

\section{PEMBAHASAN}

\section{Kondisi Masyarakat Timor Leste}

Republik Demokratik Timor Leste (RDTL) adalah sebuah negara di sebelah utara Australia dan bagian timur pulau Timor. Wilayah negara ini juga meliputi pulau Kambing atau Atauro, Jaco, dan enklave Oecussi-Ambeno di Timor Barat. Timor Leste dulu adalah salah satu provinsi di Indonesia, yaitu provinsi ke-27. Timor Leste secara resmi merdeka pada tanggal 20 Mei 2002. Ketika menjadi anggota PBB, mereka memutuskan untuk memakai nama Portugis "Timor Leste" sebagai nama resmi negara.

Kepala Negara Republik Timor Leste adalah seorang presiden, yang dipilih secara langsung dengan masa bakti selama 5 tahun. Meskipun fungsinya hanya seremonial, presiden Timor Leste memiliki hak veto undang-undang. Perdana Menteri dipilih dari pemilihan multi partai dan diangkat/ditunjuk dari partai mayoritas sebuah koalisi mayoritas. Sebagai kepala pemerintahan, Perdana Menteri mengepalai Dewan Menteri atau Kabinet dalam Kabinet Pemerintahan. Parlemen Timor Leste hanya terdiri dari satu kamar saja dan disebut Parlamento Nacional. Anggotanya dipilih untuk masa jabatan selama lima tahun. Jumlah kursi di parlemen antara 52 dan 65 tetapi saat ini berjumlah 65. Undang-Undang Dasar Timor Leste didasarkan konstitusi Portugal.

Timor Leste secara administratif dibagi menjadi 13 distrik: Aileu, Ainaro, Baucau, Bobonaro, Cova-Lima (Suai), Dili, Ermera, Lautem (Lospalos), Liquica, Manatuto, Manufahi (Same), Oecussi-Ambeno (Pante Makasar), Viqueque 
(Cabira-Oan). Nama-nama yang berada di antara tanda kurung adalah ejaan alternatif yang sering dipakai pada masa integrasi.

Perekonomian masyarakat Timor Leste sebagian besar termasuk kelas ekonomi dengan pendapatan menengah ke bawah oleh Bank Dunia dan berada di peringkat 158 dalam daftar HDI. Hal ini menunjukkan rendahnya tingkat perkembangan perekonomian masyarakat. Jumlah penduduk di Timor Leste masih banyak yang buta huruf. Walaupun telah merdeka, Timor Leste masih sangat bergantung pada pasokan barang-barang kebutuhan pokok dari negara tetangga. Secara politik, Timor Leste masih banyak bergantung pada Portugal. Selain itu, Timor Leste mengadopsi mata uang Dolar Amerika Serikat sebagai mata uang yang mengakibatkan daya beli rakyat jauh menurun jika dibandingkan ketika masih menjadi provinsi Indonesia.

Pada tahun 2005 penduduk Timor Leste diperkirakan berjumlah 1.040 .880 jiwa. Penduduk Timor Leste merupakan campuran antara suku bangsa Melayu dan Afrika, sebagian kecil keturunan Portugis. Mayoritas penduduk Timor Leste beragama Katolik (93\%), diikuti Protestan (3\%), Islam (1\%), dan sisanya Buddha, Hindu (1\%, masing-masing 0,5\%), dan aliran kepercayaan (2\%). Karena mayoritas penduduk beragama Katolik, kini terdapat tiga keuskupan (diosis) yaitu: Diosis Dili, Diosis Baucau dan Diosis Maliana yang baru didirikan pada tanggal 30 Januari 2010 oleh Paus Benediktus XVI.

Timor Leste memiliki 2 bahasa resmi, yaitu Bahasa Tetun dan Bahasa Portugis. Selain itu, dalam konstitusi disebutkan pula bahwa Bahasa Inggris dan Bahasa Indonesia dijadikan bahasa kerja. Dalam praktik keseharian, masyarakat banyak menggunakan bahasa Tetun Portugis sebagai bahasa ucap. Sementara, bahasa Indonesia banyak dipakai untuk menulis. Banyak mahasiswa dan dosen lebih memilih menggunakan bahasa Indonesia sebagai bahasa pengantar dan menulis karangan ilmiah. Selain itu, terdapat pula belasan bahasa daerah, di antaranya: Bekais, Bunak, Dawan, Fataluku, Galoli, Habun, Idalaka, Kawaimina, Kemak, Lovaia, Makalero, Makasai, Mambai, Tokodede, dan Wetarese.

Ketika masih menjadi bagian dari Negara Kesatuan Republik Indonesia, penggunaan bahasa Portugis dilarang. Saat ini, bahasa Portugis di Timor Leste diajarkan dan dipromosikan secara luas dengan bantuan dari Brasil dan Portugal, meskipun terdapat keengganan dari beberapa kalangan muda berpendidikan. Menurut Laporan Pembangunan PBB 2006, hanya kurang dari 5\% dari penduduk Timor berbicara bahasa Portugis secara fasih. Meskipun demikian, validitas laporan ini dipertanyakan oleh para anggota institut linguistik nasional Timor, yang mempertahankan pendapat bahwa bahasa Portugis diucapkan hingga 25\% dari penduduk Timor. Seiring dengan bahasa lokal lainnya, bahasa Tetum merupakan bahasa yang paling umum digunakan untuk berkomunikasi, sementara itu bahasa Indonesia masih banyak digunakan di media dan perguruan tinggi. Sebagian besar kata dalam bahasa Tetum berasal dari bahasa Portugis, tetapi juga terdapat kata-kata serapan dari bahasa Indonesia, contohnya adalah notasi bilangan.

\section{Keberadaan Bahasa Portugis di Timor Leste}

Proses perkembangan bahasa Portugis di Timor Leste masih banyak masalah. Penggunaan bahasa Portugis tidak merata di kalangan masyarakat karena hanya bisa dimengerti dan 
digunakan oleh kalangan yang terdidik. Walaupun sudah mengerti bahasa Portugis, sebagian besar penduduk yang melek huruf pun tetap mengunakan bahasa daerahnya masing-masing. Hal ini terjadi karena pada saat menjadi bagian dari pemerintahan Indonesia, penggunaan bahasa Portugis dalam percakapan keseharian dilarang, sedangkan penggunaan bahasa Tetun dan bahasa Indonesia didorong untuk disebarluaskan.

Selain kondisi sebagaimana dipaparkan di atas, masyarakat Timor Leste juga berasal dari 300 suku-bangsa, dengan 16 macam bahasa yang berbeda. Dari keenambelas bahasa tersebut, bahasa Tetun merupakan bahasa lokal yang paling banyak digunakan sampai saat ini. Kebanyakan masyarakat Timor Leste bisa mengunakan maksimal 4 bahasa dalam berkomunikasi satu sama lain. Kondisi demikian menjadi masalah baru ketika konstitusi Republik Demokratik Timor Leste telah mengesahkan, lewat pasal 13 alinea 1, bahwa Bahasa Portugis and Bahasa Tetun adalah bahasa ofisial (bahasa resmi) Republik Demokratik Timor Leste. Bahasa Portugis yang terkubur selama pemerintahan Indonesia telah hadir kembali, sedangkan Bahasa Tetun (bahasa ibu Timor Leste, meskipun ada bahasa daerah tersendiri di setiap wilayah Timor Leste) yang mengalami perubahan selama masa Kolonialis Portugis dan Indonesia, yaitu Tetun Terik (bahasa Tetun asli) ke dalam Tetun Prasa (bahasa Tetun yang banyak menyerap kosakata dari Bahasa Portugis dan Bahasa Indonesia) tidak ditata dengan benar.

Bahasa Tetunya tidak ditempatkan dalam kurikulum pendidikan selama rezim Soeharto. Akibatnya, buku-buku dalam bahasa Tetun jarang ditemukan, kecuali kitab dan beberapa buku dan diktat gereja yang diterjemahkan dalam bahasa
Tetun oleh para pastor. Bahasa Tetun yang sudah membudaya ini menjadi kurus oleh ulah penjajah, dan para linguistik butuh waktu lebih untuk menata bahasa ibu tersebut.

Perubahan administrasi pemerintahan yang berujung pada berubahnya kebijakan bahasa di Timor Leste turut memberi dampak pada sistem pendidikan dari Taman Kanak-kanak sampai universitas. Bahasa pengantar telah berubah dari bahasa Indonesia ke bahasa Portugis dan Tetun. Ini membuat guru maupun murid mengalami kesulitan dalam proses belajar-mengajar. Buku pelajaran harus diterjemahkan ke dalam bahasa Portugis dan Tetun, sedangkan buku-buku pelajaran yang didatangkan dari negara-negara CPLP (Komunitas Negara Berbahasa Portugis) sulit digunakan para guru karena kebanyakan berasal dari kaum yang belum fasih berbahasa Portugis.

Masalah ini menjadi semakin rumit apabila dicermati lagi masalah minat pendidikan masyarakat Timor Leste. Setiap tahun banyak pelajar Timor Leste yang memilih untuk kuliah di Indonesia karena bahasa Indonesia lebih mudah dipahami dan biaya kuliah di Indonesia lebih murah dibandingkan dengan Portugal, Australia, dan negara-negara lain. Masalahnya adalah apakah sekembali dari Indonesia mereka harus mengikuti kursus Portugis lagi. Proses seperti ini sedang terjadi di Timor Leste. Generasi yang berbekal bahasa Indonesia ini harus berhadapan dengan generasi yang baru lahir di era kemerdekaan, yakni masyarakat Timor Leste yang, karena mulai beradaptasi di lingkungan 'Portugis', lebih fasih berbicara dengan bahasa tersebut. Ruang sekolah adalah salah satu tempat dua generasi ini bertemu. Generasi berlidah bahasa Indonesia ini berperan sebagai pengajar. Karena itu, dapat 
dibayangkan kesulitan komunikasi yang terjadi akibat beda-lidah bahasanya.

\section{Pendekatan Pembelajaran Bahasa Secara Komunikatif}

Pendekatan komunikatif dalam pembelajaran bahasa Portugis berkenaan dengan gagasan tentang pentingnya perhatian terhadap konteks ekstra linguistik. Dalam konteks nyata yang luas, komunikasi sebagai fungsi utama dalam penggunaan bahasa. Dengan menitikberatkan pada fungsi utama bahasa sebagai alat komunikasi, pembelajaran bahasa dan pengembangan bahan ajar bahasa tidak mengedepankan struktur bahasa dengan komponen-komponen dan unsur-unsurnya secara terpisah-pisah dan berkecil-kecil, tetapi lebih menekankan pada penggunaan dan pemahaman bahasa dari fungsi utamanya, yaitu melakukan komunikasi dengan mengandalkan penggunaan kemampuan komunikatif.

Pendekatan komunikatif mengarahkan pembelajaran pada kemampuan bahasa untuk memahami atau mengungkapkan gagasan dengan menggunakan berbagai unsur bahasa dan ungkapanungkapan yang disesuaikan dengan situasi dan kondisi komunikasi. Kemampuan komunikatif itu terdiri atas penguasaan tiga komponen utama, yakni (1) kemampuan bahasa (language competence), yang meliputi berbagai unsur bahasa yang digunakan dalam berkomunikasi lewat bahasa, termasuk struktur, kosakata, prosodi , dan makna, (2) kemampuan strategis (strategic competence), yaitu kemampuan untuk menerapkan dan memanfaatkan komponen-komponen kemampuan bahasa dalam berkomunikasi lewat bahasa senyatanya, dan (3) mekanisme psiko-fisiologis (psychophysiological mechanism), yaitu proses psikis dan neurologis yang digunakan dalam berkomunikasi lewat bahasa. Secara singkat, dapat dikatakan bahwa kemampuan komunikatif adalah kemampuan untuk menggunakan bahasa sesuai dengan situasi nyata, baik secara reseptif maupun secara produktif.

Pendekatan komunikatif berorientasi pada proses belajar-mengajar bahasa berdasarkan tugas dan fungsi berkomunikasi. Prinsip dasar pendekatan komunikatif ialah (a) materi harus terdiri dari bahasa sebagai alat komunikasi, (b) desain materi harus menekankan proses belajar-mengajar dan bukan pokok bahasan, dan (c) materi harus memberi dorongan kepada pelajar untuk berkomunikasi secara wajar ( Siahaan dalam Pateda, 1991:86).

Dalam pendekatan komunikatif, yang menjadi acuan adalah kebutuhan pelajar dan fungsi bahasa. Pendekatan komunikatif berusaha membuat pelajar bahasa memiliki kecakapan berbahasa. Dengan sendirinya, acuan pokok setiap unit pelajaran ialah fungsi bahasa dan bukan tata bahasa. Dengan kata lain, tata bahasa disajikan bukan sebagai tujuan akhir, tetapi sarana untuk melaksanakan maksud komunikasi.

Strategi belajar-mengajar dalam pendekatan komunikatif didasarkan pada cara belajar siswa/mahasiswa aktif, yang sekarang dikenal dengan istilah Student Centered Learning (SCL). Cara belajar aktif merupakan perkembangan dari teori Dewey Learning by Doing (1854-1952) (lihat Pannen, dkk.2001:42). Dewey sangat tidak setuju dengan rote learning 'belajar dengan menghafal'. Dewey menerapkan prinsip-prinsip learning by doing, yaitu mahasiswa perlu terlibat dalam proses belajar secara spontan/ mahasiswa terlibat secara aktif dalam proses belajar-mengajar. 


\section{Penerapan Pendekatan Komunikatif dalam Pembelajaran Bahasa Portugis}

Penerapan pendekatan komunikatif (bandingkan Djiwandono, 2011) pada pembelajaran bahasa Portugis yang sesuai dengan kebutuhan komunikatif diarahkan pada pengembangan kemampuan komunikatif, yakni kemampuan linguistik (linguistic competence), kemampuan sosiolinguistik (sociolinguistic competence) kemampuan wacana (discourse competence), dan kemampuan strategis (strategic competence). Pendekatan komunikatif memiliki ciri (a) acuan berpijaknya adalah membimbing peserta didik dan fungsi bahasa, (b) tujuan belajar bahasa adalah membimbing peserta didik agar mampu berkomunikasi dalam situasi yang sebenarnya, (c) silabus pengajaran ditata sesuai dengan fungsi pemakaian bahasa, (d) peranan tatabahasa dalam pengajaran bahasa tetap diakui, (e) peran pengajar sebagai pengelola kelas dan pembimbing peserta didik dalam berkomunikasi diperluas, dan (f) kegiatan belajar didasarkan pada teknik-teknik kreatif peserta didik sendiri, dan peserta didik dibagi dalam kelompok-kelompok kecil.

Betolak dari ciri-ciri di atas, pendekatan komunikatif memunculkan sejumlah metode baru dalam pembelajaran bahasa kedua. Bahasa ditegaskan fungsinya sebagai alat komunikasi. Oleh karena itu, pelajar bahasa harus mampu berinteraksi secara lisan ataupun tulis. Pembelajaran harus menguasai kaidah-kaidah atau aturan-aturan kebahasaan serta mampu menggunakannya dalam berbagai kegiatan sehari-hari. Dalam pelaksanaan pembelajaran, pengajar dapat merancang proses pembelajaran dengan menggunakan bahan ajar yang bersumber dari teks otentik,misalnya, kutipan dari surat kabar (Iskandarwassid dan Sunendar, 2008: 55-56).

Melalui penerapan pendekatan komunikatif, pembelajaran dikembangkan sesuai dengan komunikasi sehingga memungkinkan terjadinya proses penggunaan bahasa untuk mengomunikasikan informasi tertentu yang dilakukan secara interaktif. Dalam hal ini, interaksi merupakan salah satu aspek penting dalam kegiatan pengomunikasian gagasan. Kegiatan ini terjadi, baik dalam komunikasi di masyarakat maupun komunikasi di dalam kelas. Interaksi bukan sekedar perbuatan aksi yang diikuti reaksi, tetapi perlu adanya perbuatan aksi dan reaksi yang timbal balik (Malamah-Thomas, 1987:7). Dalam kegiatan belajar-mengajar aksi dan reaksi timbal balik terjadi antara guru dan siswa.

Interaksi yang terjadi dalam kegiatan belajarmengajar di kelas memiliki karakteristik yang berbeda dengan karakteristik interaksi di luar kelas. Larsen-Freeman (1986: 130) menjelaskan karakteristik interaksi belajar-mengajar sebagai berikut.

(1) Aktivitas yang dilaksanakan dalam kegiatan belajar-mengajar berpusat pada siswa. Artinya, siswa yang harus aktiif dalam melaksanakan praktik penggunaan bahasa. Keterlibatan siswa dalam kegiatan belajar-mengajar merupakan salah satu karakteristik yang menonjol dari interaksi kelas.

(2) Aktivitas yang dilaksanakan dalam kegiatan belajar-mengajar mengarah secara langsung pada latihan atau praktik penggunaan bahasa baik secara lisan maupun tulis. Praktik penggunaan bahasa memiliki peranan yang sangat penting dalam pengajaran bahasa, karena pengajaran yang hanya difokuskan pada 
pemahaman kaidah bahasa tidak akan berpengaruh pada performansi aktual baik dalam berbicara maupun menulis. Pernyataan ini sesuai dengan pendapat Cazden (1972:138) yang menyatakan bahwa performansi gramatikal yang merupakan pengetahuan implisit tidak berpengaruh pada performansi aktual jika tidak dilatihkan.

(3) Aktivitas yang dilaksanakan dapat membina dan mengarahkan kemampuan siswa dalam memilih dan menata kata, frase, atau pun kalimat yang sesuai dengan faktor-faktor penentu tindak komunikasi. Faktor-faktor yang dimaksudkan meliputi siapa partisipan wicara, untuk tujuan apa, dalam situasi bagaimana, dalam konteks apa, dengan jalur dan media mana, dan dalam peristiwa apa.

(4) Aktivitas yang dilaksanakan dalam kegiatan belajar-mengajar mengarah pada kreativitas penggunaan bahasa bukan hanya penggunaan bahasa yang bersifat mekanik. Aktivitas yang dilaksanakan harus benar-benar memberikan kesempatan kepada pelajar untuk menggunakan bahasa secara kreatif dengan jalan bebas memilih apa yang akan diungkapkan dan bagaimana mengungkapkannya. Latihan-latihan yang bersifat mekanik harus diminimalkan karena tidak memberikan kesempatan pada pelajar untuk berkreasi dalam memilih dan menata bahasanya sendiri.

Agar aktivitas interaksi belajar-mengajar sebagaimana yang telah diuraikan di atas dapat dicapai, guru harus dapat berperan sebagai individu yang mampu memberikan bimbingan, memantau kegiatan siswa, menciptakan latihan-latihan kreatif, dan dalam kesempatan yang lain dapat bertindak sebagai teman komunikasi bersama-sama dengan siswa (Littlewood, 1981). Interaksi dalam kegiatan belajar-mengajar berasal dari dan terletak pada siswa. Siswa harus mendapat kesempatan dalam interaksi komunikatif yang bermakna. Dalam hal ini siswa berperan sebagai subjek didik, sedangkan guru bertindak sebagai penyuluh, penganalisis kebutuhan, dan pembimbing siswa dalam berlatih berkomunikasi secara wajar (Finnocchiaro dalam Brumfit, 1983:90).

Satu hal lagi yang perlu mendapat perhatian dalam adalah kegiatan-kegiatan yang direncanakan dalam kegiatan belajar-mengajar harus sesuai dengan kebutuhan siswa. Kegiatan yang sesuai dengan kebutuhan siswa akan memotivasi belajar siswa (Larsen-Freeman, 1986:133; dan Rodrigues, 1983:59). Motivasi yang tinggi akan dapat meningkatkan keberhasilan seseorang dalam belajar (lambert dalam Materu, 1985:58). Hal ini terjadi karena dengan motivasi yang tinggi, siswa terdorong untuk mengetahui, kemudian melakukan sesuatu untuk dapat menerima apa yang ingin diketahuinya tersebut. Peningkatan motivasi siswa dalam belajar dapat dilihat pada adanya keterlibatan secara aktif siswa terhadap hal-hal yang dipelajarinya. Sebaliknya, pengajaran yang kurang sesuai dengan kebutuhan siswa akan sangat membosankan, sehingga motivasi belajar siswa menjadi rendah (Richterich, 1983:2).

Dalam kegiatan belajar-mengajar di kelas, interaksi memiliki peranan yang sangat penting, karena interaksi memungkinkan terjadinya proses belajar-mengajar. Sejalan dengan pernyataan tersebut Van Lier (1988) menyatakan bahwa belajar hanya terjadi dalam interaksi dan melalui interaksi. Bahkan, Rivers (1987:3) menegaskan bahwa interaksi merupakan kunci keberhasilan dalam belajar bahasa. Hal ini dapat diterima karena pada 
hakikatnya bahasa adalah sarana komunikasi dan interaksi.

Belajar bahasa yang mendukung keberhasilan penguasaan bahasa adalah belajar melalui interaksi yang komunikatif. Larsen dan Freeman (1986) menyebutkan bahwa pola interaksi kelas yang komunikatif meliputi (1) aktivitas belajar berpusat pada siswa, (2) aktivitas mengarah pada praktik penggunaan bahasa, (3) aktivitas tersebut membina kemampuan siswa untuk menata dan memilih unsur-unsur bahasa secara tepat, dan (4) aktivitas kelas membina kreativitas siswa dalam menggunakan bahasa, bukan membentuk kemampuan bahasa secara mekanik.

Dalam interaksi pembelajaran bahasa, guru merupakan salah satu faktor penting. Gremo, Holec, dan Riley (dalam Ellis, 1990:77) menyatakan bahwa dalam interaksi belajar di kelas guru memiliki hak, di antaranya adalah (1) berpartisipasi dalam semua percakapan, (2) memulai percakapan, (3) menetapkan panjang-pendeknya percakapan, (4) menutup percakapan, (5) menetapkan atau menolak partisipan lain, (6) membukan lahan percakapan, (7) menjadi satu-satunya pusat percakapan bila ada partisipan lain memulai percakapan, (8) menetapkan urutan giliran dalam percakapan, dan (9) menetapkan banyaknya kesempatan yang boleh dipergunakan oleh masing-masing partisipan.

Dalam paradigma komunikatif, strategi pembelajaran menekankan pada aktivitas siswa untuk mengalami, bukan menghafal. Strategi tersebut tecermin dalam aktivitas sebagai berikut.

(1) Siswa harus mengonstruksikan pengetahuan dan kemampuan di benak mereka sendiri.

(2) Siswa belajar dari mengalami, dengan cara mencatat sendiri pola-pola bermakna dari pengetahuan baru.
(3) Pengetahuan tidak dapat dipisah-pisahkan menjadi fakta-fakta atau proposisi yang terpisah, tetapi mencerminkan kompetensi yang dapat diterapkan.

(4) Siswa perlu dibiasakan memecahkan masalah, menemukan sesuatu yang berguna bagi dirinya, dan bergelut dengan ide-ide.

(5) Pengetahuan dan keterampilan itu diperluas secara bertahap dari konteks yang terbatas.

(6) Tugas guru adalah memfasilitasi agar pengetahuan dan keterampilan baru bermakna bagi siswa, memberi kesempatan kepada siswa untuk menemukan dan menerapkan ide mereka sendiri, dan menyadarkan siswa untuk menerapkan strategi mereka sendiri.

(7) Penting bagi siswa tahu untuk apa ia belajar, dan bagaimana ia menggunakan pengetahuan dan keterampilan itu.

(8) Belajar efektif itu dimulai dari lingkungan belajar yang berpusat pada siswa, yakni dari aktivitas guru akting di depan kelas, siswa menonton ke aktivitas siswa akting dan berkarya, guru mengarahkan.

\section{SIMPULAN}

Sebagai bahasa nasional, bahasa Portugis perlu dimasyarakatkan bagi seluruh bangsa di Timor Leste. Salah satu upaya pemasayarakatan bahasa Portugis yang paling efektif adalah melalui proses pembelajaran di sekolah. Agar pemasyarakatan bahasa Portugis melalui pembelajaran tersebut dapat berhasil secara optimal, guru perlu mengembangkan praktik pembelajaran yang lebih inovatif sehingga dapat meningkatkan motivasi belajar siswa dan gaya belajar siswa yang mendukung tercapainya hasil belajar yang maksimal 
Pendekatan komunikatif mengarahkan pembelajaran pada kemampuan bahasa untuk memahami atau mengungkapkan gagasan dengan menggunakan berbagai unsur bahasa dan ungkapanungkapan yang disesuaikan dengan situasi dan kondisi komunikasi. Dalam pendekatan komunikatif, yang menjadi acuan adalah kebutuhan

Ahmad, Z.A. 2012. Perencanaan Pembelajaran dari Desain sampai Implementasi. Yogyakarta: Pedagogia

Allegro, P. 2012. Situasi dan Problem Bahasa di Timor Leste,http://aklahat.wordpress.com/2012/ 03/08/situasi-dan-problem-bahasa-di-timor-leste/ (diakses 18 Desember 2013).

Asrori, M. 2008. Psikologi Pembelajaran. Bandung : CV Wacana Prima Bahasa Portugis di Timor Leste,http://id.wikipedia.org/wiki/Timor_Leste diakses 18 Desember 2013

Boud, D. Dan Felleti, G.I. 1997. The challenge of problem based learning. London: Kogapage

Bown, Jennijer. 2006. Locus of Learning and Affective Strategy Use: Two Factors Affecting Success in Self-Instructed Language Learning, dalam Jurnal Foreign Language Annals. Vol. 39. No. 4 Winter 2006Brown, H. Douglas. 1987. Principles of Language Learning and Teaching. New Jersey: Prentice-Hall.

Edwards, H. Cliford, et.all. 1988. Planning, teaching, and evaluating: a competency approach. Chicago: Nelson-Hall.

Johnson, Elaine B. 2002. Contextual Teaching and Learning. California: Corwin Press. inc.

Jonassen, D.H. 1999. Designing constructivist learning environments. Dalam Reigeluth, C.M. (Ed): Instructional-design theories and models: A new paradigm of instructional theory, volume II. Pp. 215-239. New Jersey: Lawrence Erlbaum associates, Publisher.

Kavasoglu, Mehtap. 2009. Learning Strategy Use of Pre-Service Teachers of English Language at pelajar dan fungsi bahasa. Pendekatan komunikatif berusaha membuat pelajar bahasa memiliki kecakapan berbahasa.

\section{DAFTAR RUJUKAN}

Mersin University, dalam Jurnal Procedia Social and Behavioral Sciences 1 (2009), Volume: 1: 993-997.

Littlewood, W., 1984. Communicative Language Teaching. Cambridge : Cambridge university Press.

Maley, Alan, 1986. The Practice of Communicative Teaching. Pergamon Book Ltd.

Murray, Bokyung. 1998. Students' Language Learning Strategy Use and Achievement in The Korean as A Foreign Language Classroom, dalam Jurnal Foreign Language Annals No. 4 Vol. 43

Nur, Muhammad. 2000. Strategi-Strategi Pembelajaran. Surabaya: Pusat Studi Matematika dan IPA Sekolah, Unesa.

Sudrajat, Akhmad. 2011. Pendekatan, Strategi, Metode, Teknik, dan Model Pembelajaran, (dalam

http://akhmadsudrajat.wordpress.com/2008/09/1

2/ pendekatan-strategi-metode-teknik-danmodel-pembelajaran/,), diakses pada 12 Februari 2011.

Sunaendar, dadang dan Iskandarwassid. 2008. Strategi Pembelajaran Bahasa. Bandung: PT Remaja Rosdakarya

Suyatno dan Subandiyah, Heny. 2001. Metode Pembelajaran. Jakarta: Direktorat PLP Depdiknas.

Syahid, A. 2003. Pengembangan Bahan Ajar Matakuliah Rancangan Pembelajaran Dengan Menerapkan Model Elaborasi. Tesis, Tidak Diterbitkan. UM: PPS. 